\title{
Potencialidades investigativas para a violência de gênero: utilização da análise de discurso
}

\author{
Discourse analysis: research potentialities to gender violence
}

Mariana Porto Ruwer deAzambuja ${ }^{1}$

Conceição Nogueira ${ }^{2}$

\footnotetext{
${ }^{1}$ Programa RS

Socioeducativo - Eixo II (Apoio eAcompanhamento de Egressos), Centro de Educação Profissional São João Calábria. RuaAracaju 650, Nonoai. 91740-320 Porto Alegre RS. mariruwer@pop.com.br ${ }^{2}$ Instituto deEducação e Psicologia, Departamento de Psicologia, Universidade do Minho.
}

Abstract In the last few years we see the growing use of the terms "discourse" and "discourses analysis" in academic and research contexts, frequently without a precise definition. This fact opens space for critics and mistakes. The aim of this paper is to show a brief contextualization of discursivestudies, aswell astasks/ steps to D iscourse Analysis process by the Social Construcionism perspective. As examples we used fragments of an interview with a Family Doctor about gender violence. In the results we detach the potential of Discourse Analysis to deconstruct the existing discourses to subsequently (re)construction in the way to a more holistic view about gender violence problem.

Key words Discourse analysis, Social construcionism, Gender violence
Resumo Nos últimos anos, assistimos ao crescimento da utilização das expressões "discurso" e"análise de discurso" em diversos contextos acadêmi cos e de pesquisa, muitas vezes sem uma defini ção precisa, abrindo precedentes para confusões e críticas. 0 objetivo deste artigo é apresentar uma contextualização breve dos estudos discursivos, bem como as tarefas/passos do processo de análise de discurso sob a perspectiva do construcionismo social. U tilizamos como exemplo fragmentos de uma entrevista realizada com uma médica defamília sobrea violência de gênero. Dentre os resultados, destacamos 0 potencial da análise de discurso para a desconstrução dos discursos existentes e posterior ( re) construção em direção a uma abordagem mais integradora para o problema da violência de gênero.

Palavras-chave Análise de discurso, Construcionismo social, Violência de gênero 
Introdução

Nos últimos anos, assistimos ao crescimento da utilização da expressão "discurso" em diversos contextos acadêmicos e de pesquisa. $N$ as palavras de Phillips e Jorgensen ${ }^{1}$, "discourse has been a fashionable term", muitas vezes sendo utilizado indiscriminadamente e sem uma definição precisa. Do mesmo modo, a "análise de discurso" tem sido descrita e utilizada para as mais diversas investigações, abrindo precedentes para confusões e críticas. 0 objetivo deste artigo é apresentar uma contextualização breve do campo dos estudos discursivos, bem como suas tarefas ou passos. Para isto, utilizamos como exemplo fragmentos de uma entrevista realizada no âmbito do doutoramento em psicologia social da primeira autora (com orientação da segunda autora).

0 estudo das situações de violência vividas por mulheres se justifica pelo fato deste ser um fenômeno universal, que ocorre em todo o mundo, com prejuízos consideráveis para as vítimas. Apesar deser uma reivindicação antiga do movimento feminista, somente a partir dos anos noventa é que houve uma transformação nas concepções de governantes e instituições internacionais sobre a violência praticada contra as mulheres, passando a ser reconhecida como uma questão de direitos humanos e de saúde pública. As pesquisas realizadas em várias partes do mundo mostraram que é um problema muito mais grave do que previamente se acreditava, necessitando uma intervenção urgente ${ }^{2-4}$. N estes casos, frequentemente, 0 sistema de saúde éo primeiro (senão o único) ponto de contato com uma mulher que sofre violência, visto ser nos hospitais e centros de saúde que busca ajuda para suas feridas físicas e psicológicas 5 . Assim, estudar o modo como os(as) profissionais de saúde estão lidando com estas situações é de grande importância. De modo particular, os(as) médicos(as) de família, inseridos no contexto dos cuidados primários em saúde, são importantes atores de transformação, visto ser de sua responsabilidade não só o tratamento, mas também práticas de prevenção e promoção da saúde.

Devido a sua complexidade, as diversas formas de violência vividas pelas mulheres devem ser entendidas como um fenômeno social, possuidor de um caráter revelador das estruturas de dominação da sociedade. Faz-se necessário, portanto, estudar todas as formas de violência, estejam elas naturalizadas pela cultura ou protegidas por ideologias e/ ou instituições sociais aparentemente respeitáveis, tais como a família, a escola, a empresa e o Estado $0^{6,7}$. Neste sentido, utilizamos a expressão "vio- lência de gênero" em lugar de "violência doméstica" ou "violência contra a mulher", seguindo o entendimento dos movimentos feministas de que esta é uma questão política, uma forma de exercício de poder. A importância de utilizá-la se fundamenta no pressuposto de que a violência é, de alguma forma, influenciada por (ou influencia) relações de gênero, incluindo a violência doméstica entre pessoas hetero e/ ou homossexuais (física, sexual, econômica e psicológica); abuso sexual e estupro; torturas sexuais e estupros em situações de guerra civil, conflitos comunitários e étnicos, entre outras ${ }^{8}$. Para dar conta da complexidade deste fenômeno, acreditamos que a análise de discurso seja uma importante ferramenta potencializadora da investigação, pois permite desvelar as relações de saberpoder inerentes à problemática e seu estudo.

\section{O paradigma epistemológico \\ da análise crítica de discurso}

Qualquer pessoa que inicie seu percurso na análise dediscurso (e, mesmo, a mais experiente) fica confusa com a multiplicidade de abordagens analíticas disponíveis nas ciências humanas e sociais como tal denominadas. Ainda que haja muitas semelhanças, também existem muitas diferenças quanto ao modo de fazer a análise, suas influências e pressupostos básicos. Algumas são mais influenciadas pela etnometodologia eanálise da conversação, outras estão ligadas ao pós-estruturalismo ou ao construcionismo social. Ou seja, não existe um posicionamento único sobre a análise de discurso $0^{9}$. Trata-se mais de um conjunto de abordagens interdisciplinares que podem ser usadas para explorar diversos domínios sociais através de diferentes tipos de estudos. Desta forma, também não existe consenso sobre o que é o discurso ou sobre o modo de analisá-lo. As diferentes perspectivas oferecem suas próprias sugestões e definições, competindo na apropriação dos termos "discurso" e"análise de discurso"1.

De acordo com Viviene Burr ${ }^{10}$, a tradição francesa do estruturalismo edo pós-estruturalismo tem sido desenvolvida por autores interessados em questões sobre identidade, personalidade, alterações sociais e relações de poder, tais como Wendy HoIlway, I an Parker, Chris Weedon eValerieWalkerdine. Alguns destes(as) pesquisadores(as) também utilizam conceitos psicanalíticos para explicar a personalidade ea subjetividade, o que tem sido campo deintensos debates e conflitos dentro do construcionismo social. Por outro lado, existe quem se interesse pelo discurso de um modo diferente. As qua- 
lidades performativas do discurso - ou seja, o que as pessoas fazem com suas falas ou escritos, o que tentam obter ao falar ou escrever - têm sido um campo muito produtivo. Para isto, se apóiam na teoria do ato da fala, na análise da conversação ena etnometodologia. 0 foco das pesquisas e escritos, nesta tradição, está no modo como os relatos são construídos e nos efeitos produzidos nos falantese ouvintes, nos dispositivos retóricos usados pelas pessoas e os modos como são empregados. Não há uma preocupação especial com a personalidade, a subjetividade ou o poder e, tampouco, utilização de conceitos psicanalíticos. Para a autora, estas duas tradições, apesar de distintas, não são incompatíveis. Simplesmente refletem preocupações diferentes de pessoas que trabalham sob o "guarda-chuva" do construcionismo social.

A este respeito, N ogueira et al. ${ }^{11}$ apoiam-se em Tomás I bañez para afirmar que o construcionismo social é a escola que melhor se adequa ao pensamento pós-moderno na psicologia, podendo incluir perspectivas como a psicologia crítica, a psicologia discursiva, a análise do discurso ou 0 pós-estruturalismo. Como movimento intelectual, o pós-modernismo, tanto em suas versões mais radicais quanto nas mais moderadas, representa um grande desafio para o conhecimento, questionando e rejeitando os pressupostos fundamentais do modernismo: a noção de verdade última, o estruturalismo (idéia de que o mundo como o vemos é resultado de estruturas escondidas) e as metanarrativas (ou as grandes teorias). Enfatiza a coexistência de uma multiplicidade e de uma variedade de formas de vida dependentes das situações, o pluralismo.

A análise de discurso, nas suas diversas variações, é apenas uma (a mais visível) das abordagens existentes no construcionismo social. Seu ponto de partida é a premissa da filosofia linguística estruturalista e pós-estruturalista de que nosso acesso à realidade sempre se dá através da linguagem, pois é através desta que criamos as representações (que nunca são um simples reflexo de uma realidade preexistente) que contribuem para a construção da realidade. A linguagem não é apenas um canal através do qual a informação subjacente a estados mentais, comportamentos ou fatos do mundo écomunicada. Pelo contrário, éuma "máquina geradora" que constitui o mundo social, bem como as identidades e as relações sociais. Isto significa afirmar que alterar um discurso éum modo de transformar o mundo social. Ao pensar o discurso como uma prática social, al go queconstrói o mundo em vez de apenas refletí-lo, a análise de discurso promove o desenvolvimento de uma prática política, analisando o modo como os processos sociais participam na manutenção das estruturas de opressão $0^{1,11}$.

Portanto, a análise de discurso é muito mais do que um método de análise de dados, implicando uma mudança epistemológica radical na forma de desenvolver a pesquisa e de construir conhecimentos. Phillips e Jorgensen ${ }^{1}$ afirmam que, apesar de poder ser utilizada em todas as áreas de investigação, não pode ser empregada com todos os tipos de fundamentos teóricos. Especialmente, não pode ser usada como um simples método de análise de dados desvinculado de seus fundamentos teóricos e metodológicos. Sua utilização, nas palavras das autoras, se fundamenta em um "pacote completo" que contém: (a) premissas filosóficas (ontológicas e epistemológicas) com relação ao papel da linguagem na construção social do mundo; (b) modelos teóricos; (c) guias metodológicos para abordar um domínio de pesquisa e (d) técnicas específicas para a análise. Teoria emé todo estão de tal forma interrelacionados que o pesquisador deve aceitar suas premissas filosóficas básicas a fim de utilizar a análise de discurso. Apesar de dever formar um conjunto integrado, cada pesquisador(a) pode criar seu próprio "pacote" através da combinação de elementos de perspectivas de análise de discurso diferentes e, até mesmo, de perspectivas analíticas não-discursivas. A abordagem multiperspectivada é positivamente avaliada, pois oferece diferentes formas de conhecimento sobre um fenômeno e, consequentemente, uma compreensão mais abrangente. Contudo, este ecletismo não significa que as diferentes abordagens possam ser reunidas de modo disparatado. Deve haver uma coerência nesta integração, tomando-se cuidado com as diferenças e semeIhanças filosóficas, teóricas emetodológicas de cada abordagem.

Por fim, a análise crítica de discurso se distingue pelo seu foco crítico, seu amplo âmbito e pelo engajamento político. É uma pesquisa politicamenteenvolvida com reivindicações emancipatórias que procura ter efeitos nas práticas e nas relações sociais. Seu objetivo principal érevelar as conexõesentre linguagem, poder eideologia, bem como descrever o modo como o poder e a dominação são produzidos e reproduzidos na prática social através de estruturas discursivas de interação ${ }^{9}$.

\section{O processo da análise de discurso}

Para exemplificar as tarefas/passos do processo de análise de discurso, utilizamos fragmentos de uma 
entrevista piloto realizada no âmbito do doutoramento em psicologia social da primeira autora, cujo objetivo é analisar o discurso de médicos(as) de família sobre a violência de gênero para identificar os efeitos do discurso psicológico em suas práticas. Como vemos, as marcas/pressupostos do construcionismo social já se fazem presentes no próprio delineamento do tema de pesquisa. No exemplo apresentado, ao invés de conceber a fala da entrevistada como representativa de suas opiniões ou pensamentos - ou seja, como (re)apresentação dealgo "interno" - busca-seidentificar os efeitos discursivos e o modo como estes constróem práticas.

Delimitado o tema da pesquisa, devemos definir o material a ser analisado e os sujeitos de pesquisa. Na presente investigação, escolhemos como participantes médicos(as) de família que exercem suas atividades no contexto dos cuidados primários em saúde. Esta escolha justifica-se pelo fato dos serviços de saúde frequentementeserem o primeiro e, muitas vezes, o único ponto de contato com mulheres vítimas de violência conjugal ${ }^{5}$. Acre ditamos que os(as) médicos(as) de família, devido ao vínculo eà continuidade dos cuidados prestados, estão em uma posição privilegiada para detectar eintervir nas situações de violência conjugal entre suas pacientes. Desta forma, realizou-seuma entrevista semi-estruturada com tópicos que versavam sobre a formação e experiências profissionais da entrevistada, seu contato com situações de violência de gênero, compreensão sobre a problemática, estratégias utilizadas para lidar com o problema, dificuldades e conhecimentos/cursos deformação frequentados.

A entrevista foi realizada na universidade onde a entrevistada atua como professora, gravada e depois transcrita na íntegra, tendo duração aproximada de cinquenta minutos. A esterespeito, mais uma vez, existem concepções epistemológicas características do construcionismo social. Stubbe et al. ${ }^{9}$ afirmam que a análise dos dados já se inicia com a transcrição, a transformação das falas em texto escrito, pois toda a transcrição é uma aproximação, uma reedição parcial da gravação em que se baseia; nunca é neutra ou recupera plenamente o texto falado. Uma vez que o processo de transcrição é, inevitavelmente, seletivo, envolve umacerta dose de interpretação e análise. Desta forma, o material gravado foi transcrito o mais detal hadamente possível, destacando pausas, alterações na entonação vocal, suspiros, risos e outras manifestações, sendo o "sistema de transcrição" adotado bastante simples, onde:

$M=$ fala da entrevistadora
$\mathrm{Dr} \underline{\mathrm{a}}=$ fala da entrevistada

$[\ldots]=$ pequenas pausas

("número" s.) = pausas maiores, com marcação de tempo. Ex: (5 s.)

$\underline{\mathrm{XXX}}=$ palavra pouco clara

$(-)=$ palavra incompreensível

Suspiros, risos e outras manifestações são colocadas entre parênteses. Ex: (tom irônico); (risos); (suspiro).

Com o material transcrito em mãos, a tarefa seguinteé certificarmos dequeconstitui realmente um (ou mais) discurso(s). De acordo com Nogueira e Fidalgo ${ }^{12}$, nem tudo é discurso, existindo dois critérios centrais para sua definição. Em primeiro lugar, um fragmento de conversação ou texto é relevante se os(as) seus(uas) participantes são representativos do grupo/comunidade que o(a) investigador(a) tenha identificado como protagonista na relação social estudada. A representatividade, aqui, não está ligada à noção estatística, mas ao fato de a pessoa entrevistada ter uma referência grupal que lhe permita expressar, de forma típica, o conjunto de vivências de seu grupo. Trabal ha-se, portanto, com o conceito de "sujeito coletivo"13. 0 segundo critério é a existência ef eitos discursivos, os quais não dizem respeito a efeitos psicológicos individuais no(a) falanteou ouvinte. Os efeitos discursivos são aqueles que operam por cima do nível individual [...]. A tarefa do analista consiste em percorrer os textos procurando todas as possíveis leituras e identificar aquelas que sejam mais adequadas para a relação social que está em consideração ${ }^{12}$ [grifo das autoras].

No material em análise, podemos afirmar que a longa experiência profissional da entrevistada (mais de vinte anos atuando em cuidados primários) a capacita para falar em nome da categoria "médicos(as) de família" e a coloca numa posição representativa do seu grupo. Neste aspecto, sua fala pode ser considerada discurso. Quanto ao segundo critério, sua atuação tanto no sistema de saúde (centro de saúde) quanto no sistema educativo (universidade) possui efeitos discursivos: ao tratar mulheres vítimas de violência, seu discurso constitui práticas de cuidado/intervenção; ao ministrar aulas e relatar suas experiências aos(às) futuros(as) médicos(as), suas práticas constituem regras/prescrições. As práticas de cuidado/intervenção e as regras/prescrições são o que chamamos de "efeitos discursivos".

0 passo seguinte no processo de análise da entrevista éa leitura repetida das transcrições. As grandes categorias que começam a emergir da recorrência de temas são relacionadas à literatura e, numa leitura mais detalhada, refinadas em cate- 
gorias recorrentes menores, os "repertórios" ou "discursos"14. Dito de outra forma, são elaboradas conexões em torno das questões de pesquisa; detalhados e sinalizados os significados construídos no texto e o modo como estes objetos são construídos ${ }^{15}$.

0 tema principal da entrevista foi o contato da entrevistada com situações de violência praticada nas famílias que atende, não apenas contra muIheres, mas também jovens e crianças de ambos os sexos. Abrange o relato de diferentes situações, 0 modo e a intensidade com que aparecem na sua vivência profissional e suas explicações para o fenômeno. Dentre as diversas análises que a entrevista pode suscitar, destacamos especialmente dois temas, os quais chamamos de "discurso sociológico" e"discurso psicológico".

0 discurso sociológico é identificado a partir dos recursos discursivos utilizados pela médica de família para explicar o motivo de encontrar tantas mulheres e jovens vítimas de agressões entre suas pacientes, o qual remete ao campo sociológico. A violência é vista como algo que faz parte da vida destas pessoas, conforme aparece na utilização de expressões como "o tradicional", "muito frequente", "o hábito" ou "a parte cultural" presentes no fragmento abaixo:

Drạ: É assim, o tradicional, aqui nesta zona, são os maridos baterem nas mulheres.

$M:$ Ahã [...]

Drạ: É $[\ldots]$ ]é muito frequente. $E[\ldots]$ os pais castigarem extremamente os filhos!

$M$ : Ahã.

Drạ: Ou porque há o hábito de bater na [... ] mulher, na mulher.

$M$ : Sim. Pelo fato de ser mulher [... ]?

Drẹ: Batem.

$\mathrm{M}:[\ldots]$ já batem [...] quando é jovem [... ] e depois quando for adulta, também.

Dra: : [... ] batem [... ]

Drạ: Eu, eu acho quetem muito a ver com [... ] com a parte cultural $[\ldots]$

$M:$ Ahã $[\ldots]$

Drạ: (- -) tem muito a ver [... ] ah [... ] quejá nasceram, em casas, que [...] que as mães eram batidas! E que elas também eram batidas, pelos pais!

$M: \operatorname{Sim}[\ldots]$

Drạ: [... ] depois casam e continuam aquilo.

A partir da construção da violência de gênero como algo que diz respeito à cultura, aos aspectos históricose sociais, seria esperado que as intervenções realizadas se inserissem neste âmbito, com, por exemplo, medidas de promoção da igualdade de gênero, a promoção de uma cultura de nãoviolência na comunidade atendida pelo centro de saúde ou grupos demulheres para o enfrentamento da violência ${ }^{16}$. Lembrando que os cuidados primários também são responsáveis pela prevenção e promoção da saúde, uma ação poderia ser o questionamento do mito da inviolabilidade da privacidade familiar, o que poderia ser obtido com a promoção de uma maior visibilidade para o fenômeno. Contudo, não éo queacontece. As situações de violência relatadas permanecem restritas ao contexto da consulta médica, conforme o fragmento abaixo demonstra:

Drä: muitas vezes nem os vizinhos sabem [... ] não sabem quem que fica dentro da casa. $E[\ldots]$ e [... ] e quando nos contam a nós, ah [... ] e aquilo é uma coisa muito restrita. $\mathrm{Hã}[\ldots]$ aquilo que [...] que eu faço, normalmente, é [...] é [...] é tentar que $[. .$.$] que elas [... ] porque, normalmen-$ te, estas pessoas tem uma auto-estima um bocadito baixa.

$M:$ Ahã [... ]

Dra. é tentar reforçar um bocadinho a autoestima, para as pessoas sentirem que [... quer dizer, não tem o direito de ser batidas [... ]

$M:$ Ahã $[\ldots]$

Dre.: [... ] muito menos pela pessoa com quem [... ] vivem [... ] diariamente, né?

As soluções apontadas se dirigem ao nível individual, como o encaminhamento para a psicoterapia e outras estratégias individualizantes, tais como o "reforço da auto-estima", "a abordagem centrada na pessoa" ou o estabelecimento de "estratégias de evitamento da agressão".

Drä: Estou a me lembrar de um caso, de uma senhora que é batida pelo marido, e agora apareceu-mea filha dela, que ébatida pelo namorado! $\mathrm{E}$ [... ] tentei trabalhar [...] também assim com a filha, e a filha [... ] acha muito bem, porque a mãe também leva!

$M:$ Hum hum [... ]

Drä: E eu fiquei um bocado [... ] (suspiro) assustada. Ah [... ] e pronto, e a filha, essa, encaminhei mesmo para [... ] para psicoterapia porque acho que é uma jovem ainda [... ]

$M: \operatorname{Sim}[\ldots]$

$\operatorname{Dr} \underline{a}:[\ldots]$ novinha, que [... ] ainda poderá [ ... ] ter algum benefício nisso, não é?

$M:$ Hum hum [...]

Drạ: [ ... ] a mãe já [... tem [... ] a idade que tem [... ] se calhar, já [... ] já não terá muito, mas também não temos, assim, mãos da [... ] da psicoterapia como nós queremos, não é? Porque se tivéssemos era diferente. 
Drạ: Assim, eu utilizo muito o [... ] a abordagem centrada na, na [... ] na pessoa que tenho na minha frente $[\ldots]$

$M:$ Ahã.

$D r$ â: $E[\ldots]$ e com algumas reformulações, com [... ] fazendo levar a pessoa a compreender aquela situação, e [... ] a tentar chegar lá primeiro [...] ver como éque pode [... ] separar isso, como éque pode conseguir lidar com as coisas de outra maneira, e[ ... ] e[... ] até $[\ldots]$ acabar às vezes por não $[\ldots]$ não [... ] ter quelevar tanto, porque começa a perceber quando é que [... ] vem pancada [... ]

$M$ : Ahã.

$\operatorname{Dr}$ ä: E a ter [... ] hã [... ] saber gerir um bocado isto, de modo a evitar apanhar, né.

M : Sim, sim [... ]Q ue ela possa perceber alguma situação, algum indicador, digamos, que 0 companheiro dê $[\ldots]$

Drạ: Exato, que dê [... ] que vai levar e que elas possam defender né $[\ldots]$

Assim, percebemos que há uma aparente contradição entre as causas apontadas para a violência (socioculturais) e as medidas utilizadas para enfrentá-las (individuais), constatação quenos leva ao tema seguinte.

0 discurso psicológico diz respeito às construções discursivas da violência como um problema individual edefundo psicológico - tal como a autoestima baixa - ou como um problema familiar. De modo particular, a questão da transgeracionalidadeda violência tem sido muito discutida no campo da psicologia a partir de expressões como "famílias disfuncionais", "famílias caóticas", "famílias desorganizadas" ou "círculo da violência". Conforme já discutido em outro momento ${ }^{17}$, especialmente na psicologia, existe uma tendência de utilizar explicações deterministas para o fenômeno da intergeracionalidade da violência. Enraizada nas mais profundas crenças de estudiosos(as) e do senso comum, o determinismo da intergeracionalidade foi, de certa forma, criado e legitimado pela própria psicologia que, desde seus primórdios, tem buscado estabelecer padrões de normalidade para os comportamentos humanos. Assim, o jargão "o abusado de hoje será o abusador de amanhã" se tornou quase que uma "lei". As explicações mais psicologicistas normalmente utilizam análises da personalidade do abusador, visto como "doente", "perturbado emocionalmente" ou "perverso", estando entre as razões para esta "perturbação" fatores sociobiológicos (transmissão genética) ou comportamentais, sendo estes últimos geralmente associados à noção de "comportamento aprendido" ou de "socialização".
A respeito da socialização, Nogueira ${ }^{19}$, apoiando-se nas idéias de Sandra H arding, afirma que se trata de uma perspectiva essencialista que se insere no programa empirista da psicologia tradicional. Abordagem dominante nos estudos de gênero na psicologia social da metade do século XX, surgiu como uma tentativa de mudar o foco de atenção do biológico para o social. Segundo esta concepção, desde o nascimento, as crianças aprendem a internalizar prescrições apropriadas para o ser feminino ou ser masculino segundo as normas sociais. A partir de processos demodelagem eimitação, a personalidadeéformada demodo definitivo, passando a constituir uma característica individual, estável e inerente aos indivíduos. A distinção entre inato e aprendido é meramente semântica, pois os padrões de social ização internalizados são concebidos como específicos epersistentes ao longo da vida, como uma "essência". Ou seja, apesar de procurar acrescentar os fatores socioculturais, a teoria da social ização permanecefuncionando dentro deuma visão essencialista, em que um comportamento, após aprendido, se torna inalterável.

No contexto da entrevista em análise, percebemos que os discursos identificados (sociológico e psicológico) atuam articuladamente na construção da violência de gênero como um problema individual - ou, no máximo, intrafamiliar. Ao invés de constituírem uma oposição, ambos os discursos estabelecem uma relação paradoxal: as explicações para as causas da violência utilizam recursos discursivos do campo sociológico (a tradição, a cultura), mas de uma forma essencialista; as intervenções realizadas se inserem no campo psicológico, através de dispositivos individualizantes (psicoterapia, reforço à auto-estima, estratégias de evitação). Em síntese, ambos os discursos posicionam as vítimas como responsáveis individualmente pelas vivências de violência conjugal, bem como pelo enfrentamento e superação desta situação. Consequentemente, o papel do(a) profissional se restringe a auxiliá-las a encontrar respostas para 0 problema, numa lógica de "cura por esbatimento dos sintomas".

Retomando a proposta de apresentar o processo de análise de discurso, é importante lembrar as críticas apontadas por Antaki et al. ${ }^{19}$ para erros comuns em diversos tipos de estudos qual itativos, o que chamam de "pseudo-análises". No exemplo que trazemos, restringirmos a análise de discurso à simples constatação do paradoxo social versus psicológico seria uma "pseudo-análise por localização de elementos", que consiste em apenas identificar e localizar elementos ou características dos dados sem apresentar nenhuma informação ou 
reflexão adicional; ou uma "pseudo análise circular", em que as citações empregadas são explicadas a fim de sustentar a existência do repertório/discurso em termos desta mesma entidade. De modo semelhante, restringirmos a análise à "avaliação" das intervenções da entrevistada seria realizar uma "pseudo-análise baseada na tomada de posição ou juízo de valor", fundamentada em aspectos como a moral, a posição política ou pessoal do(a) analista a fim de censurar (ou fomentar) alguma fala. $M$ ais do que um julgamento da atitude individual da profissional cujo discurso está sendo analisado, devemos compreender sua fala como fundamentada nosrecursos socialmente disponíveis para compreender o fenômeno da violência. E, para isso, é necessário identificar as condições de possibilidade deste(s) discurso(s).

\section{Condições de possibilidade}

Chamamos de condições de possibilidade todos os aspectos (históricos, sociais, culturais, ideológicos, econômicos, etc.) que, de forma articulada, engendram um determinado discurso. Para que a análise de discurso realmente se identifique como crítica, tais condições devem ser esmiuçadas, questionadas e desconstruídas para que, alternativamente, novos discursos e práticas se estabeleçam. Seguindo alguns dos "passos" apresentados por Parker ${ }^{15}$, é preciso falar sobre as redes de relação que dão sentido ao texto, destacar os padrões existentes, nomear alguns discursos como compromissos sociais que tornam possíveis os arranjos sociais contraditórios e ressaltar os aspectos relacionados à ideologia e ao poder.

No tema em questão, encontramos uma rede de relação entre discursos aparentemente contraditórios (explicações sociológicas versus intervenções individuais) que constroem a violência de gênero como um problema de foro íntimo, delicado e complexo, ainda que tenha raízes socioculturais. O social entra sob a lógica da socialização discutida acima18: a "cultura" destas famílias atua como uma "essência" que, depois de internalizada, torna-se inalterável. Desta forma, filhas de mulheres agredidas passam a considerar esta situação "normal", repetindo este padrão nas suas relações afetivas devido a "processos de modelagem" ou "imitação", os quais apenas poderão ser alterados pela psicoterapia ou pelo reforço à auto-estima (estratégias individuais).

As discussões de Lavis et al..$^{20}$ sobre a integração da violência doméstica no campo dos cuidados de saúde são úteis para entendermos este paradoxo.
Segundo as autoras, apenas muito recentemente os profissionais da saúde foram chamados para intervir em um problema que, até então, era visto como predominantemente social. Esta alteração na construção da violência doméstica significa uma redução de limites entre as disciplinas, com a integração de um complexo problema social nas obrigações e responsabilidades dos(as) profissionais de saúde, o que traz vantagens, mas também alguns dilemas. A utilização do modelo médico, predominante no campo da saúde e fundamentado pelo paradigma científico da modernidade, leva à individualização dos problemas, os quais são reduzidos a categorias de diagnóstico (de doença) e de tratamento. Assumindo a perspectiva individual, 0 discurso médico redefine e reduz a complexidade dos fatores sociais e de saúde envolvidos na violência doméstica em termos dos atributos individuais da mulher agredida. Assim, podemos afirmar que o discurso sociológico anteriormente identificado se aproxima ao discurso médico, hegemônico no campo dos cuidados em saúde.

De modo semelhante, o discurso psicológico dominante é oriundo do paradigma moderno, preocupando-seem estabelecer leis, prever acontecimentos e determinar os padrões de normalidade e anormalidade. A ideologia do individualismo marcou a instauração da psicologia a partir da noção de um indivíduo moralmente autônomo, senhor de si, livre dos vínculos e determinismos universais definidos pela cultura. A psicologia científica do início do século XX, a criação de inúmeros laboratórios experimentais eo desenvolvimento da psicometria são exemplos da busca por um método objetivo para o conhecimento do ser humano, medição de seu comportamento e ajuste à ordem social vigente $e^{19,20}$.

Seguindo a lógica positivista - em que as unidades devem ser separadas para melhor serem estudadas - inicialmente, psicologia e medicina trabalharam em domínios distintos: mente versus corpo, sendo que as grandes transformações ocorridas no campo da saúde em meados do século $X X$ representam 0 auge do paradigma mecanicista. É o caso, por exemplo, da descoberta dos antibióticos e da crescente sofisticação tecnológica da medicina a partir da Segunda Guerra Mundial. Tais transformações consolidaram o modelo científico mas, paradoxalmente, também foram as causas de sua falência. Com o desenvolvimento das sociedades e a melhoria da qualidade de vida das populações, novos problemas foram colocados para o campo da saúde. 0 aumento das doenças crônico-degener ativas (diferentes ti pos de câncer, doenças do coração, hipertensão arterial, doenças men- 
tais), que não se mostram tratáveis por intervenções baseadas no modelo unicausal, representa uma crise na medicina ocidental moderna ${ }^{21}$.

Neste momento de transição no quadro de morbimortalidade (do predomínio das doenças infecciosas para o aumento das doenças crônicas), a importância de aspectos psicológicos e sociais do adoecer se tornou mais evidente, requisitando a intervenção de outras esferas do conhecimento, entre elas a psicologia. A subdisciplina psicologia da saúde surgiu neste período, buscando responder à necessidade de pensar o processo saúde-doença como um problema social. Contudo, devido às raízes históricas da própria psicologia, isto se deu a partir dos ideais do paradigma dominante, o positivista ${ }^{22}$. Desta forma, tanto a medicina comportamental quanto a psicologia da saúde inspiraram-se no behaviorismo, fazendo com que os discursos sobre a saúde ficassem marcados pela noção de que os indivíduos são responsáveis pela sua condição de saúde devido às "escolhas" feitas ou ditadas por seu "estilo de vida". Prevalece o domínio individual em detrimento das questões socioculturais. Mesmo quando passou a adotar o modelo biopsicossocial, a psicologia da saúde se deteve numa ênfase individualista, com a dominância de modelos de estresse e estratégias de enfrentamento emodel os cognitivo-sociais para processos psicológicos associados à saúde e doença, permanecendo como foco a condição de saúdedos indivíduos, seu estilo de vida e características psicológicas associadas às doenças $5^{23,24}$.

A respeito da temática em análise, Lavis et al..$^{20}$ afirmam que a abordagem individualista posiciona as mulheres que vivenciam violência doméstica como objetos de processos de psicopatologização, suprimindo relatos alternativos de resistência eignorando o amplo contexto social e político que perpetua e sustenta a violência. Desta forma, se estabeleceuma relação hierárquica desigual, em que os(as) profissionais de saúde são posicionados como especialistas detentores de poder sobre suas pacientes. A relação assimétrica de poder que se estabelece serve para protegêlos(as) do envolvimento emocional que tais situações podem acarretar, o que é condizente com o modelo positivista de ciência, pautado pela neutralidade. A violência de gênero, ao ser reduzida a uma categoria diagnóstica, torna-se um problema controlável e manipulável pelos recursos oferecidos pelo discurso médico. Adota-se um discurso semelhante ao utilizado para lidar com doenças crônicas, em que o papel do(a) profissional é "empoderar" o(a) paciente para introduzir mudanças em seu "estilo de vida" ou situação social a fim de alcançar melhori- as na saúde. E, nestecaso, a única intervenção considerada efetiva (cura) é o abandono da relação conjugal violenta.

Retomando material analisado, percebemos que as diversas intervenções individualizantes se inserem nesta perspectiva. 0 reforço à auto-estima é uma estratégia de "empoderamento" e o encaminhamento para a psicoterapia se insere na lógica (redutora) da classificação diagnóstica. Logo, a introdução da violência de gênero como um problema de saúde não foi acompanhada por um novo modelo detrabalho, sendo vista como apenas mais um problema de saúde entre tantos outros. $\mathrm{Na}$ falta de um modelo próprio, as questões relativas à violência doméstica são manejadas de acordo com os repertórios discursivos disponíveis - os discursos médico e psicológico - sendo a individualização e a medicamentalização da violência de gênero os principais (e mais perigosos) efeitos discursivos. Constroem-se práticas de cuidado e intervenção a-políticas, descontextualizadas e redutoras que responsabilizam as vítimas.

D ando seguimento à proposta de "desconstruir" os discursos hegemônicos, a análise de discurso também deve procurar identificar potencialidades, "Iinhas de fuga" dentro do próprio discurso dominante. N o trecho seguinte, podemosidentificar que o sentimento de despreparo e a posterior busca por cursos de formação podem representar um momento de abertura para novas possibilidades, reflexões e questionamentos do saber construído.

$M: E[\ldots]$ e a senhora se sente preparada pra lidar com essas situações?

Drâ.: Hã [... E É assim [... ] tem al gumas dificuldades, não é?

$M:$ Hum hum $[\ldots]$

Drạ: Hã [ ... ] já fiz algum [... ] alguma formação nessa área [... ]

$M: \operatorname{Sim}[\ldots]$

Drä: Porque, de fato [... ] quer dizer, a pessoa, sente dificuldade e procura formação nessas áreas [... ]

M: Hum hum $[\ldots]$

Drạ: [... ] ejá fiz alguma.

$M$ : Hum hum $[\ldots]$

Drä: E digamos [... ] que é sempre uma situação que [... mexe conosco, não é $[\ldots]$ ?

$M$ : Hum hum $[\ldots]$

Drä: M esmo que a gente não queira, e na hora tenha que ser muito imparcial e tem que [... ] não se pode deixar afetar [...]

$M:$ Hum hum $[\ldots]$

Drâ:: M as no fundo é uma coisa que nos afeta, não é? 
Numa primeira análise, o sentimento de incapacidade, de sentir dificuldades para lidar com estas situações pode ser entendido como uma "fraqueza" na formação profissional da entrevistada. Indo além da simples crítica, o construcionismo social pretende realizar uma descrição mais positiva do potencial científico, sendo seu objetivo analisar as interações e as práticas sociais daí resultantes ${ }^{11}$. Logo, estes momentos de busca por formação/capacitação profissional podem servir como espaços de construção de novos saberes. 0 contato com referenciais da psicologia crítica pode servir como um "chamamento para a ação", tal como descrito por Murray e Campbel/25. Segundo estes autores, é necessário que os(as) profissionais da saúde entrem no fórum político como ativistas ao invés de se limitarem a serem apenas "trabalhadores(as)", saindo da posição de observadores(as) para a de comprometidos(as) socialmente, preocupando-se com o impacto potencial das pesquisas na melhoria da qualidade de vida. O papel da ação e da crítica pode assumir diversas formas, indo desde a participação em movimentos sociais atéa exposição teórica dos pressupostos que sustentam as práticas psicológicas. Através da apresentação dos referenciais da epistemologia feminista e da psicologia crítica, as idéias dominantes na disciplina podem ser alteradas, mostrando como elas individualizam ereduzem as noções de saúde e doença.

Este é o caso, por exemplo, da utilização da terminologia "mulher vítima" ou "mulher sobre vivente" de violência. Deacordo com Lavis et al. ${ }^{20}$, a representação das mulheres que vivenciam violência doméstica como vítimas as posiciona como fracas, passivas, dependentes dos outros e com pouco controle sobre suas vidas. Tal construção é condizente com a posição subjetiva tradicional e com o modelo de resposta evidente no paradigma médico de cuidado. Ignorar a capacidade de agência feminina serve para invalidar sua experiência subjetiva e excluí-la deum papel ativo naintervenção. Por outro lado, a utilização da palavra "sobrevivente" significa reconhecer suas estratégias de resistência, ligando-se à noção de uma mulher ativa, de força, que busca lidar ativamente com 0 problema. Portanto, fundamentalmente, a alteração no modo de cuidado oferecido para situações de violência de gênero envolve a renegociação das posições subjetivas tradicionais na interação médico(a)-paciente ea desconstrução das relações de poder subjacentes.

\section{Consideraçõesfinais}

O objetivo principal deste artigo era mostrar os pressupostos e fundamentos da análise de discurso, bem como apresentar uma amostra de como pode ser realizada. M ais do que simplesmente descrever um "método", pretendíamos dar visibilidade às potencialidades investigativas deste paradigma para um campo particular de estudo, a violência de gênero. Acreditamos que as análises aqui apresentadas - ainda que incipientes - indicam de que forma os conhecimentos e saberes existentes as verdades - podem ser questionadas, desconstruídas e, fundamentalmente, reconstruídas de modo mais positivo. A violência de gênero é um tema que, cada vez mais, tem atraído a atenção de governantes e estudiosos(as) e, apesar das diversas pesquisas, legislações e interven ções realizadas em todo o mundo, os números tendem cada vez mais a crescer ${ }^{2-5}$. Por um lado, isto representa uma maior visibilidade do fenômeno e, portanto, uma vitória; por outro lado, o aumento do número de casos registrados expõe a fragilidade destas intervenções que não conseguem, de fato, estancar 0 problema. N este sentido, torna-se importante refletir sobre o tipo de cuidado quetem sido oferecido a estas mulheres. A análise aqui apresentada indica que as intervenções são microfocadas, dire cionadas para o âmbito individual e marcadas pelo discurso médico do paradigma da modernidade que ainda domina na área da saúde, desconsiderando 0 amplo contexto social e político que sustenta a violência de gênero. Acreditamos quea análise de discurso representa uma importante ferramenta potencializadora para a investig(ação), uma vez que permite desconstruir os saberes existentes - para, em seguida, reconstruí-los de modo mais abrangente, com um foco nas relações sociais e nos jogos de força e poder, através dos suportes oferecidos pela psicologia da saúdecrítica, do construcionismo social e do feminismo. 


\section{Colaboradores}

M Azambuja realizou a pesquisa bibliográfica, a coleta dedadose redigiu o artigo. C N ogueira orientou a pesquisa, revisou e aprovou a redação do artigo.

\section{Referências}

1. Phillips $L$, Jorgensen $M$. Discourse Analysis as theory and method. London: Thousand Oaks; New Delhi: Sage Publications; 2002.

2. Organização das Nações Unidas. Centro para o Desenvolvimento Social e Assuntos Humanitários. Gabinete das $\mathrm{N}$ ações Unidas de Viena. Estratégias de combate à violência doméstica: manual de recursos. Lisboa: Organização das N ações U nidas/Direcção-Geral da Saúde; 2003.

3. Ellsberg M, H eise L. Researching Violence Against Women: A Practical Guide for Researchers and Activists. Washington, D.C.: World Health Organization; 2005.

4. World Health Organization. Department of Gender, Women and Health Family and Community Health. Addressing violence against women and achieving the Millennium Development Goals. Geneva: World Health Organization; 2005.

5. Ertürk Y. [Preface]. In: World Health Organization. Multi-country study on women's health and domestic violence against women: summary report of initial results on prevalence, health outcomes and women's responses. Geneva: World Health Organization; 2005. p. vii-vii.

6. Minayo $M$. The inclusion of violence in the health agenda: historical trajectory. Cien Saude Colet 2006; 11(2): 375-383.

7. M inayo $M C$, Souza E. Violência e saúde como um campo interdisciplinar e de ação coletiva. Hist. cienc. saude- $M$ anguinhos 1998; 4(3):513-531.

8. Skinner T, Hester M, Malos H. Methodology, feminism and gender violence. In: Skinner T, Hester $M$, $\mathrm{M}$ alos $\mathrm{H}$, editors. Researching Gender Violence. Feminist M ethodology in Action. Cullompton: Willan Publishing; 2005. p. 1-22.

9. Stubbe $M$, Lane $C$, Hilder J, Vine E, Vine B, M arra $M$, Holmes J, Weatherall A. Multiple discourse analyses of a workplace interaction. Discourse Studies 2003; 5(3):351-388.

10. Burr V. An Introduction to Social Constructionism. London: Routledge; 1995.

11. Nogueira C, N eves A, Barbosa C. Fundamentos construcionistas, sociais e críticos para o estudo do gênero. Psicologia: Teoria, Investigação e Prática 2005; 2:1-15.

12. Nogueira C, Fidalgo L. Análise do discurso: a tarefa e o poder das palavras. Avaliação Psicológica: Formas e Contextos 1995; 3:181-188.

13. Martinelli M. O uso de abordagens qualitativas na pesquisa em serviço social. In: M artinelli $M$, organizadora. Pesquisa qualitativa: um instigante desafio. São Paulo: Veras; 1999. p. 11-30.

14. Peace P. Balancing power: the discursive maintenance of gender inequality by wo/men at university. $\mathrm{Fe}$ minism \& Psychology 2003; 13(2):159-180.

\section{Agradecimentos}

Com o apoio do Programa Alban, Programa de Bolsas de Alto Nível da Comunidade Européia para a América Latina, bolsa no E05D 053211BR.
15. Parker I. Qualitative Psychology. Introducing radical research. New York: O pen University Press; 2005. p. 88-104.

16. Meneghel $S$, Barbiani $R$, Brener $C$, Teixeira $G$, Steffen $H$, Silva L, Dalla Rosa M, Balle R, Brito SGR, Ramão S. Cotidiano ritualizado : grupos de mulheres no enfrentamento à violência. Cien Saude Colet 2005; 10(1):111118.

17. Azambuja M. Violência doméstica contra crianças: uma questão de gênero? In: Strey $M$, Azambuja $M$, Jaeger $F$, organizadoras. Gênero, violência e políticas públicas. Coleção Gênero e Contemporaneidade, vol. 2. Porto Alegre: EDIPUCRS; 2004. p. 259-290.

18. Nogueira C. Contribuições do construcionismo social a uma nova psicologia do gênero. Cadernos de Pesquisa 2001;112:137-153.

19. Antaki C, Billig M, Edwards D, Potter J. El análisis del discurso implica analizar: crítica de seis atajos analíticos. Atenea Digital [serial on the Internet] 2003 [cited 2006 Nov 18]; 3: 13-35. Available from: http:// antalya.uab.es/athenea/num3/antaki.pdf

20. Lavis V, Horrocks C, Kelly N, Barker V. Domestic Violence and Health Care: Opening Pandora's Box Challenges and Dilemmas. Feminism \& Psychology 2005; 15(4):441-460.

21. Queiroz M. O paradigma mecanicista da medicina ocidental moderna: uma perspectiva antropológica. Rev. Saude Publica 1986; 20:309-317.

22. Dimenstein M. A cultura profissional do psicólogo e o ideário individualista: implicações para a prática no campo da assistência à saúde. Estudos de Psicologia 2000; 5(1):95-121.

23. Gioia-M artins D, Rocha Júnior. A. Psicologia da Saúde e o novo paradigma: novo paradigma? Psicologia. Teoria e Prática 2001; 3(1):35-42.

24. Nelson G, Pancer S, Hayward K, Kelly R. Partnerships and participation of community residents in health promotion: experiences of the Highfield Community Enrichment Project (Better Beginnings, Better Futures). Journal of Health Psychology 2004; 9(2):213-227.

25. Murray $M$, Campbell $C$. Living in a material world: reflecting on some assumptions of health psychology. Journal of Health Psychology 2003; 8(2):231-236.

Artigo apresentado em 13/04/2007

Aprovado em 02/08/2007

Versão final apresentada em 15/08/2007 